\title{
Are independent mobility and territorial range associated with park visitation among youth?
}

\author{
Jenny Veitch*, Alison Carver, Clare Hume, David Crawford, Anna Timperio, Kylie Ball and Jo Salmon
}

\begin{abstract}
Background: Parks are important for providing opportunities for physical activity among youth. Apart from engaging in physical activity whilst visiting a park, active transportation (e.g. walking or cycling) to parks is potentially an additional source of physical activity. Previous research has shown that a major barrier to young people visiting parks is their inability to visit parks unaccompanied by an adult. It is not known; however, whether young people who have greater independent mobility and territorial range (ability to move around their neighbourhood alone or with friends, unaccompanied by an adult) are more likely to visit parks. This study examined park visitation and travel mode to parks and whether independent mobility and territorial range were associated with park visitation among youth living in disadvantaged areas of Victoria, Australia.

Methods: In 2010-11, 311 youth aged 8-16 years self-reported their park use, active transport, independent mobility to parks, and territorial range. Logistic regression models determined the odds of park visitation (once per week or more) according to independent mobility and territorial range, adjusting for key covariates.

Results: Overall, $75 \%$ of participants reported visiting parks, and 37\% visited their 'usual' park at least once per week. Of those who reported visiting parks, $87 \%$ travelled to the park they usually visited using active transport: $57 \%$ walked, $22 \%$ cycled, and $8 \%$ used a scooter/skateboard. Just $15 \%$ and $13 \%$ of youth regularly walked or cycled alone to parks/playgrounds respectively, and 25\% and 19\% regularly walked or cycled with friends or siblings (no adults) respectively. For the $84 \%$ who reported having parks/playgrounds within walking distance from home, those who regularly walked alone to parks $(\mathrm{OR} 3.61 ; \mathrm{Cl}=1.67,7.80)$, and regularly walked $(\mathrm{OR} 2.27 ; \mathrm{Cl}=1.14,4.55)$ or cycled $(\mathrm{OR} 3.38 ; \mathrm{Cl}=1.73,6.62)$ with friends to parks, were significantly more likely to visit a park at least once per week, compared to others.
\end{abstract}

Conclusions: This study showed that active transport is frequently used by this sample of young people to travel to parks. Findings also highlight the potential importance of providing opportunities for youth aged 8-16 years to visit local parks independent of an adult.

Keywords: Park visitation, Adolescents, Youth, Active transport, Independent mobility, Territorial range

\section{Background}

Public parks are important for providing opportunities for physical activity among youth [1] and for supporting initiatives to reduce the prevalence of obesity in young people [2-4]. Studies have shown positive associations between objectively measured availability of local parks and playgrounds and young people's physical activity $[5,6]$. Parent proxy-report and youth self-report perceptions of living within close proximity to parks have also

\footnotetext{
* Correspondence: jenny.veitch@deakin.edu.au

Centre for Physical Activity and Nutrition Research, Deakin University, 221

Burwood Highway, Burwood, VIC 3125, Australia
}

been associated with increased likelihood of being active within a park among children and adolescents $[7,8]$ and with engaging in more moderate- to vigorous-intensity physical activity among adolescents [8]. Enhancing opportunities for youth to visit parks is a promising strategy for promoting physical activity. Park use may be particularly advantageous for increasing physical activity levels in low socioeconomic status (SES) neighbourhoods where residents are at an increased risk of inactivity and associated poor health [9].

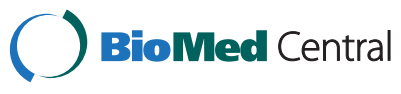

(c) 2014 Veitch et al.; licensee BioMed Central Ltd. This is an Open Access article distributed under the terms of the Creative Commons Attribution License (http://creativecommons.org/licenses/by/2.0), which permits unrestricted use, distribution, and reproduction in any medium, provided the original work is properly credited. The Creative Commons Public Domain Dedication waiver (http://creativecommons.org/publicdomain/zero/1.0/) applies to the data made available in this article, unless otherwise stated. 
Independent mobility refers to young people's freedom to move around their neighbourhood without adult accompaniment [10]. Youth with greater independent mobility tend to spend more time walking or cycling around their neighbourhood to reach places and generally also have greater 'territorial range', meaning that they are permitted to roam further from home and visit a broader range of destinations without adult accompaniment [11]. Previous research has shown that a major barrier to young people visiting parks is their inability to visit parks unaccompanied by an adult $[12,13]$. We are unaware, however, of any research that has examined whether young people who have greater independent mobility and territorial range are more likely to visit parks.

Apart from engaging in physical activity whilst visiting a park, active transportation (e.g. walking or cycling) to parks is potentially an additional source of physical activity among youth. Few studies have examined the mode of transport young people use to travel to the parks they usually visit. A study [7] in the USA found that walking and cycling to recreational sites including small and large parks was associated with frequent active use of these sites by young people [7]. However, that study did not examine whether travel to the parks was performed independent of an adult.

While access to parks from home is important for active transport to be a viable option, in low socioeconomic status (SES) neighbourhoods, youth often travel more than twice the distance of youth in higher SES areas to reach the park they usually visit [14]. This may make it more difficult for youth living in low SES neighbourhoods to use active transport to access the parks they visit. Few studies have examined park visitation or use of active transport (particularly independent of an adult) to reach the park among youth living in low SES neighbourhoods. The aims of this study were therefore to examine the frequency of park visitation and travel mode to parks among a sample of youth living in low SES areas, and to investigate whether independent mobility and territorial range on their own or with friends/siblings (unaccompanied by an adult) were associated with park visitation.

\section{Methods}

Participants for this study were recruited from the Resilience for Eating and Physical Activity Despite Inequality (READI) study, a longitudinal cohort study examining resilience to obesity among socio-economically disadvantaged women and children. The methods have been described in more detail elsewhere [15]. Data collection was conducted in October 2010 - June 2011. Ethics approval was granted by the Deakin University Human Ethics Advisory Group, the Catholic Education Office and the Department of Education and Early Childhood Development.

\section{Procedure and participants}

Briefly, women aged 18-45 years residing in 40 urban and 40 rural low SES areas of Victoria, Australia were invited to complete a postal survey regarding their dietary and physical activity behaviours. Disadvantaged areas were randomly selected from suburbs in the bottom tertile of the Victorian Socio-Economic Index for Areas (SEIFA) distribution [16] within urban and rural strata. Of these women $(n=11,940)$ who were randomly sampled from the electoral roll, 4934 consented to participate $(41 \%$ response rate). Women $(n=1457)$ with a child aged between 5-12 years were invited to complete a further questionnaire on their child's health behaviours. In total, data were collected for 636 children (44\% of eligible children). Baseline data collection was conducted between August 2007 and July 2008. In August 2010, women and children were invited to participate in this three-year follow-up study nested within the READI study, to examine adolescents' active transport and independent mobility. Parental consent to participate in the current study was obtained for 311 children/adolescents (henceforth called adolescents), who comprised $49 \%$ of the original sample. Participants aged 8-16 years completed a survey at school $(88 \%)$ or home (12\%) about their park use, active transport and independent mobility to parks in their local neighbourhood, and their territorial range from home. During survey completion a research assistant was available to assist participants understand and respond to any questions where required. Participants were provided with a small ball as compensation for their time.

\section{Measures}

\section{Park usage}

Adolescents were asked whether or not they visited parks and if so, which park they usually visited and how often they usually visited this park. Response options included: 'most days'; 'once per week'; 'several times per month'; 'once per month'; 'less than once per month'; and 'have not visited in past 6 months'. Responses were dichotomised as 'visit at least once per week' or 'not'.

\section{Travel mode to parks/playground}

Adolescents were asked to report by ticking the most appropriate response, how they typically travelled to the park that they usually visited. Response options included: 'walk'; 'ride a bike'; 'skateboard/scooter/rollerblades'; and 'car'.

\section{Independent mobility to parks}

Participants were asked if any parks/playgrounds were located within walking and/or cycling distance from their home. Those who reported living within walking/cycling distance of a park were then asked how often they usually walked to nearby parks: (a) by themselves; (b) with adult accompaniment; and (c) with friends/siblings (no adults). 
Response options included: 'never'; 'rarely'; 'sometimes'; 'often'; and 'very often'. Two dichotomous variables were derived from these responses to indicate (1) whether participants regularly (often or very often) walked alone to parks (or not) and (2) whether they regularly (often or very often) walked with friends/siblings (no adults) to parks (or not). Adolescents were asked the same questions in relation to frequency of cycling to nearby parks/playgrounds. One week test-retest reliability for these variables was established in a separate study of 48 children aged 8-9 years in 2010 and ranged from moderate $(\kappa=0.40)$ to perfect $(\kappa=1.0)$ in the case of cycling without adult accompaniment.

\section{Territorial range}

Adolescents reported how far from home they were allowed to roam on their own. Response options included: 'I am not allowed out alone'; 'within my street'; 'within 2-3 streets away from home'; 'within 15 minutes' walk from home'; and 'more than 15 minutes' walk from home'. This question was repeated in relation to how far from home they were allowed to roam with friends (unaccompanied by an adult). For each of these variables, responses were dichotomised to indicate whether or not they were allowed to roam more than 15 minutes from home. Testretest reliability for these variables was moderate $(\kappa=0.59$; 0.52 respectively).

\section{Demographics}

Mothers reported their highest level of education which was collapsed into three categories: low $=<12$ years of schooling (no formal education or year 10/equivalent); medium = 12 years of schooling (having completed year 12 or equivalent, a trade/apprenticeship, or certificate/ diploma); and high = >12 years of schooling (having a university or higher university degree). Mothers also reported their car ownership, and their child's age and sex.

\section{Data analyses}

Analyses were conducted using SPSS v21 and Stata SE v12. Descriptive analyses on the dependent and independent variables were performed. Among those living within walking/cycling distance to a park, crude logistic regression models adjusting for clustering by suburb were conducted to examine the odds of visiting their usual park at least once per week according to independent mobility to the park and territorial range. Adjusted logistic regression models controlling for sex, age, urban/rural location and clustering by suburb were also performed. Potential interactions of explanatory variables with sex and age were examined.

\section{Results}

Three-hundred and eleven adolescents completed the survey. The mean age was 12.2 years (range $8-16$ years),
$55 \%$ were attending primary school (first seven years of schooling in Australia), 45\% were boys and 70\% resided in rural areas. Almost one-third of mothers had completed more than 12 years of education, and $99 \%$ of all households had access to a car (Table 1).

\section{Park visitation}

A total of 233 adolescents (75\%) reported visiting parks. Among these, 37\% reported visiting their usual park at least once per week and $69 \%$ visited at least several times per month. Of those who reported visiting parks, $87 \%$ travelled to the park they usually visited using active

Table 1 Characteristics of study sample (2010-11 Victoria, Australia)

\begin{tabular}{|c|c|}
\hline \multicolumn{2}{|l|}{ Characteristics of the child } \\
\hline Sex (\% boys) & 44.7 \\
\hline Age (years; mean (SD)) & $12.2(2.19)$ \\
\hline Attending primary school (\%) & 55.0 \\
\hline Resides in rural area (\%) & 69.5 \\
\hline \multicolumn{2}{|l|}{ Maternal education (\%) } \\
\hline$<12$ years & 20.2 \\
\hline 12 years & 46.4 \\
\hline$>12$ years & 33.4 \\
\hline \multicolumn{2}{|l|}{ Frequency of visitation to usual park visited ${ }^{a}(\%)$} \\
\hline Most days & 15.5 \\
\hline Once per week & 21.4 \\
\hline Several times per month & 32.2 \\
\hline Once per month & 10.3 \\
\hline Less than once per month & 14.2 \\
\hline Have not visited in past 6 months & 6.44 \\
\hline \multicolumn{2}{|l|}{ Usual mode of transport used when visiting park ${ }^{\mathrm{a}}(\%)$} \\
\hline Car & 13.0 \\
\hline Walking & 57.1 \\
\hline Cycling & 21.6 \\
\hline Scooter/skateboard & 8.2 \\
\hline \multicolumn{2}{|l|}{ Independent mobility to parks (\%) } \\
\hline Regularly walks ${ }^{b}$ alone to parks/playgrounds & 15.3 \\
\hline $\begin{array}{l}\text { Regularly walks }{ }^{\mathrm{b}} \text { with friends or siblings (no adults) } \\
\text { to parks/playgrounds }\end{array}$ & 24.8 \\
\hline Regularly cycles ${ }^{c}$ alone to parks/playgrounds, & 13.2 \\
\hline $\begin{array}{l}\text { Regularly cycles }{ }^{c} \text { with friends or siblings (no adults) } \\
\text { to parks/playgrounds }\end{array}$ & 18.8 \\
\hline \multicolumn{2}{|l|}{ Territorial range (\%) } \\
\hline Allowed to roam >15 minutes from home alone & 37.0 \\
\hline Allowed to roam $>15$ minutes from home with friends & 49.5 \\
\hline
\end{tabular}

${ }^{a}$ Among those who visit park(s) $(n=233)$.

${ }^{\mathrm{b}}$ Among those who reported that a park/playground was within walking distance from home $(n=262)$.

${ }^{\mathrm{C}}$ Among those who reported that a park/playground was within cycling distance from home $(n=272)$. 
transport: $57 \%$ walked, $22 \%$ cycled, and $8 \%$ used a scooter/skateboard (Table 1).

Of the 311 adolescents, 262 (84\%) reported that parks/ playgrounds were within walking distance from home. Of these, less than one in four regularly walked or cycled independently to parks/playgrounds. Just over one-third of all participants reported that they could roam more than 15 minutes from home alone and 50\% reported that they could roam more than 15 minutes from home with friends (Table 1).

With respect to independent mobility, Table 2 shows that after adjusting for age, sex, urban/rural location and clustering by suburb, youth who reported regularly walking or cycling to parks without adult accompaniment were more likely to visit parks at least once per week. For example, the odds of visiting parks at least once per week were more than three-and-a-half times as high among participants who regularly walked alone to parks, compared with those who walked alone to parks less regularly. Furthermore, the odds of visiting parks at least once per week was more than two times higher among youth who regularly walked with friends (no adults) to parks and more than three times higher among those who regularly cycled with friends (no adults) to parks, when compared with adolescents who did not do this regularly. Territorial range was not significantly associated with frequency of park visitation. No significant interactions with age and sex were identified (data not shown).

\section{Discussion}

This study is novel as it is one of the first to examine how independent mobility and territorial range were associated with frequency of park visitation among a sample of adolescents living in low SES urban and rural areas.
We found that the majority of our sample visited parks, with more than one-third visiting at least once per week. Active transport was the most popular mode of transport used to access the park. These findings are consistent with previous research which found that among a sample of 1859 British children (mean age 10 years) 82\% usually travelled by walking or cycling when visiting the park [17]. Few other studies have examined the mode of transport young people use to visit parks; however, a recent systematic review of studies involving young people aged 3-18 years showed that active transport to destinations other than school was positively associated with physical activity [18]. Travelling to parks using active modes is likely to be an important source of physical activity among young people, particularly among youth living in low SES areas and is an important next step to examine in future research.

Territorial range was not significantly associated with likelihood of visiting a park once or more per week. This was an interesting finding as, to date, most research on territorial range has focused on sex differences and on age-related increases $[19,20]$ and has not examined children's territorial range in relation to park visitation (e.g. whether children who are allowed to roam further from home without adult accompaniment visit parks that are within walking distance of home more frequently).

The current study found that youth who reported regularly walking or cycling to parks without adult accompaniment were more likely to visit parks at least once per week. To our knowledge, no previous studies have specifically examined associations between independent mobility and park visitation; however, previous research has shown that children with greater independent mobility are more active [18] and spend more time playing

Table 2 Associations between independent mobility to parks, territorial range and visiting a park at least once per

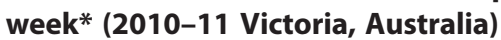

\begin{tabular}{|c|c|c|c|c|}
\hline & \multicolumn{4}{|c|}{ Visiting a park at least once per week ${ }^{a}$} \\
\hline & \multicolumn{2}{|c|}{ Unadjusted models ${ }^{\mathbf{b}}$} & \multicolumn{2}{|c|}{ Adjusted models ${ }^{c}$} \\
\hline & OR $(95 \% \mathrm{Cl})$ & $\mathbf{p}$ & OR $(95 \% \mathrm{Cl})$ & $\mathbf{p}$ \\
\hline \multicolumn{5}{|l|}{ Independent mobility } \\
\hline Regularly walks alone to parks & $3.31(1.61,6.81)$ & 0.001 & $3.61(1.67,7.80)$ & 0.001 \\
\hline Regularly walks with friends (no adults) to park & $1.72(0.88,3.36)$ & 0.110 & $2.27(1.14,4.55)$ & 0.020 \\
\hline Regularly cycles alone to parks & $2.35(1.05,5.26)$ & 0.038 & $2.10(0.85,5.21)$ & 0.110 \\
\hline Regularly cycles with friends (no adults) to park & $2.96(1.54,5.69)$ & 0.001 & $3.38(1.73,6.62)$ & $<0.001$ \\
\hline \multicolumn{5}{|l|}{ Territorial range } \\
\hline Allowed to roam >15 mins from home alone & $1.32(0.76,2.30)$ & 0.319 & $1.47(0.80,2.71)$ & 0.217 \\
\hline Allowed to roam >15 mins away from home with friends & $1.20(0.71,2.04)$ & 0.491 & $1.50(0.79,2.82)$ & 0.213 \\
\hline
\end{tabular}

${ }^{\mathrm{a}}$ Odds are for visiting a park at least once per week compared to visiting a park less than once per week.

b Logistic regressions without adjustment for covariates, controlling for clustering by suburb.

'Logistic regression controlling for sex and age, urban/rural location and clustering by suburb.

*Includes only participants who reported that parks/playgrounds were within walking $(n=262)$ or cycling $(n=272)$ distance from home.

Significant associations are shown in bold.

OR = Odds Ratio; $95 \% \mathrm{Cl}=95 \%$ Confidence Interval. 
outdoors [21,22]. For example, in an Australian study, children aged 10-12 years who reported that they were allowed to walk on their own near home were more than two and a half times as likely to spend time playing outdoors after school compared with children who were never allowed to walk on their own [21]. In a UK study among 1307, 10-11 year old children, greater independent mobility was associated with an increased likelihood of boys playing outdoors every day [22]. In these two previous studies, activity and independent mobility were selfreported and the location of the outdoor play was not specified and may have included various locations such as the yard at home, the street and/or the local park.

Although not examined in the current study, previous research has reported that road safety and 'stranger danger' appear to be major causes of parental anxiety in relation to their child's safety in the neighbourhood [23]. These concerns may cause parents to restrict their children's outdoor play, active transport and independent mobility. A recent study among adults in the US found that participants were more likely to visit local parks if they did not have to cross or travel on a high traffic speed road between home and their closest park [24]. Although this study was among adults, it would be reasonable to argue that the effects of traffic concerns may be even more detrimental to independent mobility and park visitation among youth. Conversely, features within the neighbourhood built environment, such as the presence of green spaces [25], outdoor play spaces [26] and housing density [27] may promote children's independent mobility. In order to increase opportunities for youth to access neighbourhood destinations such as parks independently of an adult, it is important to further investigate strategies to address these barriers/facilitators to increase opportunities for independent mobility.

The findings from this study are limited by the crosssectional study design which precludes causal inference, and generalisability may be limited to those living in disadvantaged areas. Public transport was not included as an option for means of transport to visit parks and this is a limitation as public transport may involve active transport (i.e. walking to a bus stop) and may also affect independent mobility. The relatively small sample size also restricted our ability to stratify by age, sex or urban/ rural residence. Participants ranged in age from 8-16 years and it is possible that park use and independent mobility varies across these ages. Further, data collection was carried out over a nine month period between October 2010 and June 2011 and although participants were asked to report their usual participation, some of the respondents' answers may have been influenced by the weather conditions at the time they completed the survey. In addition, the response categories for the item on park visitation did depend on participants' interpretation of 'several times' but this is not atypical and it is not possible to determine how this may have affected the results. Finally, when examining independent mobility to parks, only including those who reported having a park/playground within walking distance from home may have reduced heterogeneity in the distance travelled to visit the park. It is also important to acknowledge the use of self-report, although guided interviews strengthened this methodology. Additional strengths included the recruitment of youth in rural as well as urban areas and the focus on low SES neighbourhoods since this population group has been under-researched.

\section{Conclusions}

This study showed that active transport was frequently used by the young people in this sample to travel to parks and highlights the potentially important role of independent mobility for increasing park visitation among youth aged 8-16 years. In order to promote active transport and independent mobility to parks it is important for planners to site local parks within walking/cycling distance of the majority of homes or within residential areas. Further research is also required to better understand the factors that may restrict young people's independent mobility and how these concerns can be minimised to enhance opportunities for young people to visit local parks independently of an adult.

\section{Competing interest}

The authors declare that they have no competing interests.

\section{Authors' contributions}

$J V$ conducted the data analyses and drafted the manuscript. AC assisted with the data analyses and manuscript writing. $\mathrm{CH}, \mathrm{DC}, \mathrm{AT}, \mathrm{KB}$, and JS provided critical comment on the analyses and the manuscript. All authors contributed to the drafting of the manuscript and read and approved the final manuscript.

\section{Acknowledgements}

This study was supported by a linkage grant from the Australian Research Council in partnership with the Victorian Health Promotion Foundation (VicHealth). JV is supported by a National Health and Medical Research Council Early Career Research Fellowship (ID 1053426). CH is supported by a Postdoctoral Research Fellowship from the National Heart Foundation of Australia. AT is supported by a National Heart Foundation of Australia Future Leader Fellowship (ID 100046). KB is funded by a National Health and Medical Research Council Principal Research Fellowship (ID 1042442). JS is supported by a National Health and Medical Research Council Principal Research Fellowship (ID 1026216).

Received: 9 December 2013 Accepted: 4 June 2014

Published: 9 June 2014

\section{References}

1. Floyd MF, Bocarro JN, Smith WR, Baran PK, Moore RC, Cosco NG, Edwards MB, Suau LJ, Fang K: Park-based physical activity among children and adolescents. Am J Prev Med 2011, 41:258-265.

2. Alexander DS, Huber LR, Piper $C R$, Tanner AE: The association between recreational parks, facilities and childhood obesity: a cross-sectional study of the 2007 National Survey of Children's Health. J Epidemiol Community Health 2007, 2013(17):427-431. 
3. Potwarka LR, Kaczynski AT, Flack AL: Places to play: association of park space and facilities with healthy weight status among children. J Community Health 2008, 33:344-350.

4. Bell JF, Wilson JS, Liu GC: Neighborhood greenness and 2-year changes in body mass index of children and youth. Am J Prev Med 2008, 35:547-553.

5. Cohen DA, Ashwood S, Scott M, Overton A, Evenson KR, Staten L, Porter DE, McKenzie TL, Catellier D: Public parks and physical activity among adolescent girls. Pediatrics 2006, 118:1381-1389.

6. Roemmich JN, Epstein L, Rama S, Yin L, Robinson J, Winiewicz D: Association of access to parks and recreational facilities with the physical activity of young children. Prev Med 2006, 43:437-441.

7. Grow HM, Saelens BE, Kerr J, Durant NH, Norman GJ, Sallis JF: Where are youth active? Roles of proximity, active transport, and built environment. Med Sci Sports Exerc 2008, 40:2071-2079.

8. Ries AV, Voorhees CC, Roche KM, Gittelsohn J, Yan AF, Astone NM: A quantitative examination of park characteristics related to park use and physical activity among urban youth. J Adolesc Health 2009, 45:S64-70.

9. Ball K, Crawford D: Socio-economic factors in obesity: a case of slim chance in a fat world? Asia Pac J Clin Nutr 2006, 15(Suppl):15-20.

10. Hillman M, Adams J, Whitelegg J: One False Move: A Study of Children's Independent Mobility. London: PSI Publishing; 1990.

11. Mackett R, Brown B, Gong Y, Kitazawa K, Paskins J: Children's independent movement in the local environment. Built Environ 2007, 33:454-468.

12. Veitch J, Bagley S, Ball K, Salmon J: Where do children usually play? A qualitative study of parents' perceptions of influences on children's active free-play. Health Place 2006, 12:383-393.

13. Veitch J, Salmon J, Ball K: Children's perceptions of the use of public open spaces for active free-play. Children's Geographies 2007, 5:409-422.

14. Veitch J, Salmon J, Ball K: Children's active free play in local neighborhoods: a behavioral mapping study. Health Educ Res 2008, 23:870-879.

15. Ball K, Cleland V, Salmon J, Timperio AF, McNaughton S, Thornton L, Campbell K, Jackson M, Baur LA, Mishra G, Brug J, Jeffery RW, King A, Kawachi I, Crawford DA: Cohort profile: the resilience for eating and activity despite inequality (READI) study. Int J Epidemiol 2012, 42(6):1629-1639.

16. Australian Bureau of Statistics: Census of Population and Housing: Socio-Economic Indexes for Areas (SEIFA). Australia: 2006. (http://www.abs. gov.au/AUSSTATS/abs@.nsf/allprimarymainfeatures/356A4186 CCDDC4D1CA257B3B001AC22C?opendocument). Accessed on 5 June 2014.

17. Smith L, Sahlqvist S, Ogilvie D, Jones A, Griffin SJ, van Sluijs E: Is active travel to non-school destinations associated with physical activity in primary school children? Prev Med 2012, 54:224-228.

18. Schoeppe S, Duncan MJ, Badland H, Oliver M, Curtis C: Associations of children's independent mobility and active travel with physical activity, sedentary behaviour and weight status: a systematic review. J Sci Med in Sport 2013, 16:312-319.

19. Hart R: Children's Experience of Place. New York: Irvington; 1979

20. Matthews H: Making Sense Of Place: Children's Understanding Of Large Scale Environments. Hemel Hempstead: Harvester Wheatsheaf; 1992.

21. Wen L, Kite J, Merom D, Rissel C: Time spent playing outdoors after school and its relationship with independent mobility: A cross-sectional survey of children aged 10-12 years in Sydney, Australia. Int J Behav Nutr Phys Act 2009, 6:15.

22. Page AS, Cooper AR, Griew P, Jago R: Independent mobility, perceptions of the built environment and children's participation in play, active travel and structured exercise and sport: the peach project. Int J Behav Nutr Phys Act 2010, 7:17-26

23. Carver A, Timperio A, Crawford D: Playing it safe: the influence of neighbourhood safety on children's physical activity - a review. Health Place 2008, 14:217-227.

24. Kaczynski AT, Koohsari MJ, Stanis SA, Bergstrom R, Sugiyama T: Association of street connectivity and road traffic speed with park usage and park-based physical activity. Am J Health Prom 2014, 28:197-203.

25. Alparone FR, Pacilli MG: On children's independent mobility: the interplay of demographic, environmental, and psychosocial factors. Children's Geographies 2012, 10:109-122.
26. Carver A, Timperio AF, Crawford DA: Young and free? A study of independent mobility among urban and rural dwelling australian children. J Sci Med In Sport 2012, 15:505-510.

27. Broberg A, Salminen S, Kytta M: Physical environmental characteristics promoting independent and active transport to children's meaningful places. App/ Geogr 2013, 38:43-52.

doi:10.1186/1479-5868-11-73

Cite this article as: Veitch et al:: Are independent mobility and territorial range associated with park visitation among youth? International Journal of Behavioral Nutrition and Physical Activity 2014 11:73.

\section{Submit your next manuscript to BioMed Central and take full advantage of:}

- Convenient online submission

- Thorough peer review

- No space constraints or color figure charges

- Immediate publication on acceptance

- Inclusion in PubMed, CAS, Scopus and Google Scholar

- Research which is freely available for redistribution 